\title{
The Discovery of Zoonotic Protozoans in Fleas Parasitizing on Pets as a Potential Infection Threat
}

\author{
Olga Pawełczyk ${ }^{1}\left[\right.$ Marek Asman $^{1} \oplus \cdot$ Krzysztof Solarz $^{1} \oplus$
}

Received: 21 January 2020 / Accepted: 23 April 2020 / Published online: 28 May 2020

(c) The Author(s) 2020

\begin{abstract}
Purpose Fleas are insects with a high medical and veterinary importance. They may participate in spreading of many pathogenic agents, but still there is limited information about their possible reservoir or vector role for protozoans. The main aim of this study was an attempt of detection zoonotic pathogens, such as Babesia microti and Toxoplasma gondii in fleas Ctenocephalides felis felis and Ctenocephalides canis.

Methods In 2013-2017, 155 fleas were captured from domestic dogs and cats in veterinary clinics, animal shelters and pet grooming salons in Upper Silesia Region in Poland. Then, the DNA was extracted from each Ctenocephalides flea by using the ammonia method. Samples were screened for the presence of B. microti and T. gondii using PCR and nested PCR methods.

Results B. microti was reported in $6.6 \%$ of $C$. felis felis and $9.1 \%$ of $C$. canis, whereas the prevalence of coinfection with $B$. microti and T. gondii was $1.9 \%$ in cat fleas and $2.3 \%$ in dog fleas.

Conclusion This study shows the first cases of B. microti occurrence and B. microti and T. gondii coinfection in Ctenocephalides fleas. The estimation of prevalence of examined protozoans may be useful considering the possibility of infection among companion animals, as well as during presentation of the potential risk of infection in humans. In order to clarify the role of $C$. felis felis and C. canis in transmission of B. microti and $T$. gondii, the another studies with in vitro cultures and laboratory animals are needed.
\end{abstract}

Keywords Babesia microti · Toxoplasma gondii $\cdot$ Ctenocephalides felis felis · Ctenocephalides canis · PCR · Nested PCR

\section{Introduction}

Fleas are insects with a high medical and veterinary significance. Their bites usually cause an irritation and allergic reactions. Furthermore, they may transmit many pathogenic agents with zoonotic capacity, like Yersinia pestis, Francisella tularensis, as well as species from the Rickettsia and Bartonella types [1,2]. Fleas developed many ways of pathogen transportation, like blood-sucking or by infected excrements, by vertical, horizontal and mechanical transmission [3-5]. The species examined in this study, cat fleaCtenocephalides felis felis (Bouché, 1835) and dog fleaCtenocephalides canis (Curtis, 1826) are among the most

Olga Pawełczyk

olga.pawelczyk@sum.edu.pl

1 Department of Parasitology, Faculty of Pharmaceutical Sciences in Sosnowiec, Medical University of Silesia, Katowice, Poland frequently occurring external parasites affecting companion animals in the world [6].

According to our knowledge, epidemiological studies about flea prevalence on pets have been limited in Poland $[7,8]$. The occurrence of fleas in populations of domestic animals and the prevalence of zoonotic species in examined specimens are occasionally described in foreign reports [9-11]. Moreover, there is no information about the detection or possibility of Babesia microti and Toxoplasma gondii transmission by fleas.

B. microti, a protozoan, which parasitizes in erythrocytes of an intermediate host, is absorbed by ticks with blood during feeding [12-14]. Thus, babesiosis is induced by the transmission of protozoans with tick saliva to organism and by transplantation or blood transfusion from infected patient $[15,16]$. The first report about $B$. microti detection in Poland was confirmed in 1997 by Humiczewska et al. [17]. Nowadays, this parasite is abundant in the USA, in Eastern Europe, as well as in Poland [18-20]. To the main vectors 
of this pathogen belong the representatives of the Ixodina suborder, especially two of them, namely Ixodes scapularis and I. ricinus [21, 22]. The occurrence of this protozoan has been also shown in Dermacentor reticulatus [23, 24].

In this study, the second detected, cosmopolitan parasite was T. gondii, an obligatory intracellular Apicomplexa protozoan, which does not require arthropod vectors to finish its life cycle. Its prevalence ranks on high to moderate level in the natural habitat [25]. T. gondii undergoes the life cycle in two organisms - the final hosts of this protozoan are representatives of the Felidae family, whereas the role of intermediate hosts may fulfill both birds and mammals (including humans). The alimentary way is the most often reason of infection with $T$. gondii. The bradyzoites and tachyzoites occur in a raw meat, as well as in the other food products, whereas the $T$. gondii sporocysts may be present in potable water [25-27]. In recent years the concern of parasitologists about the $T$. gondii transmission has been increased, what is probably caused by detection of this species in ticks [28].

The present work was aimed at providing evidence of the identity of fleas on domestic cats and dogs in Poland and showing the presence of zoonotic protozoans, like B. microti and $T$. gondii in the examined material.

\section{Materials and Methods}

\section{Collection of Material}

Fleas have been collected from January 2013 to April 2017 from companion animals during the routine examination in veterinary clinics and animal shelters, as well as the beauty treatments in pet grooming salons in the cities of Upper Silesia Region in Poland, Central Europe. They were captured from domestic cats and dogs, directly from their skin or pelage. The material was conserved in plastic tubes with $70 \%$ ethyl alcohol. Fleas were determined to species and sex using stereoscopic microscope SZ-40 (Olympus, Japan), according to Skuratowicz key (1967) [29].

\section{DNA Extraction and Molecular Detection of Pathogens}

DNA was isolated from a single individual by using the ammonia method [30]. Fleas were placed in separate sterile plastic tubes with $100 \mu \mathrm{l}$ of $0.7 \mathrm{M} \mathrm{NH}_{4} \mathrm{OH}$. Subsequently, insects were mechanically crushed by the homogenate CAT X 120 (Ingenieurbüro CAT, M. Zipperer GmbH, Staufen, Germany) and the samples were boiled at $100{ }^{\circ} \mathrm{C}$ for $15 \mathrm{~min}$ in a heating block TB-941U (JW Electronic, Warsaw, Poland). Then, lids were opened and the samples were boiled at $100{ }^{\circ} \mathrm{C}$ for $10 \mathrm{~min}$ in order to remove the ammonia, centrifuged for $5 \mathrm{~min}$ at $12000 \mathrm{rpm}$ and the supernatant was transferred to a new plastic tube. The DNA concentration was measured using the Nanospectrophotometer Pearl (Implen, Munich, Germany).

The DNA samples were screened for the presence of pathogens using PCR and nested PCR methods. The amplification reactions were conducted in a thermal cycler MJ Mini (BioRad, California, USA). To the detection of T. gondii in fleas collected in 2013-2014 a commercial kit PK 40 (Blirt-DNA, Gdańsk) was used, which consisted of two mixes (PCR-OUT and PCR-IN). Each mix included one pair of primers, dNTP's, DNA TaqNova polymerase and reaction buffer. The detection consisted of the amplification of the gene fragment which coding the antigen protein $65 \mathrm{kDa} T$. gondii. The material was analyzed according to the manufacturer instruction. The conditions of both reactions were as follows: preliminary denaturation in $94{ }^{\circ} \mathrm{C}$ for $2 \mathrm{~min}$, then denaturation in $94{ }^{\circ} \mathrm{C}$ for $30 \mathrm{~s}$, annealing at $64{ }^{\circ} \mathrm{C}$ for $60 \mathrm{~s}$, elongation at $72{ }^{\circ} \mathrm{C}$ for $30 \mathrm{~s}$ and final elongation at $72{ }^{\circ} \mathrm{C}$ for 2 min. 40 cycles in PCR reaction were performed, whereas in nested PCR - 35. In turn, the two pair of primers Pml/ AS1, Pml/S1 and Pml/AS2, Pml/S2 specific to the fragment of B1 gene [31] were used for detection $T$. gondii in fleas collected in 2015-2017. Two-stage PCR reaction consisted of 30 and 20 cycles respectively was made, according to Sroka et al. [32] protocol.

B. microti was detected by using the two pairs of primers-Bab1/Bab4 and Bab2/Bab3 specific to the 18S rRNA gene [33]. The conditions of PCR reaction was the same as in study of Wójcik-Fatla et al. [33]. The nested PCR conditions was identical as during the first PCR reaction, but the number of reaction cycles was 30 .

The PCR products were separated electrophoretically in $2 \%$ ethidium bromide-stained gels. Then the gels were visualized under ultra violet light and photographed in the analyzer Omega 10 (Ultra-Lum, California, USA). The presence of reaction products with the size of $238 \mathrm{bp}$ and $154 \mathrm{bp}$ for B. microti, $308 \mathrm{bp}$ (Blirt DNA Gdańsk) or $531 \mathrm{bp}$ for $T$. gondii were considered positive.

\section{Results}

\section{Determination of Fleas}

In total 155 fleas were collected from the same number of pets-domestic dogs (Canis lupus familiaris) (89) and domestic cats (Felis catus) (66). Four flea species were identified from the collected material. The most frequent species was $C$. felis felis $(68.4 \%)$, followed by C. canis $(28.4 \%)$, Pulex irritans Linnaeus, 1758 (1.9\%) and Archaeopsylla erinacei (Bouché, 1835) (1.3\%). Females constituted the majority of collected individuals $(84.5 \%)$. 


\section{Flea Species Distribution on Examined Hosts}

Species diversity was greater in the material collected from domestic dogs (C. lupus familiaris), than from domestic cats $(F$. catus). The most numerous flea species caught from population of domestic dogs was C. felis felis (52.81\%), then C. canis, P. irritans and A. erinacei (Table 1). Out of the total number of fleas (66) collected from domestic cats $(F$. catus), the vast majority constituted of cat fleas ( $C$. felis felis) $(89.39 \%)$. Furthermore, dog fleas (C. canis) were also reported (Table 1).

\section{Detection of Pathogenic Factors in Fleas}

In this study, all collected cat fleas (C. felis felis) and dog fleas (C. canis) were molecularly analyzed in order to detect B. microti and T. gondii. The DNA was isolated from all Ctenocephalides fleas (150), including 106 individuals of $C$. felis felis ( 93 females and 13 males) and 44 of C. canis (33 females and 11 males). We excluded the DNA isolation from P. irritans and A. erinacei, which do not belong to specific flea species of companion animals. The present study shows the occurrence of two pathogenic species in cat and dog fleas removed from pets.

B. microti was detected both in females and males of C. felis felis and C. canis. This protozoan occurred on the similar level in both species. Its prevalence was $9.1 \%$ in $C$. canis and $6.6 \%$ in C. felis felis (Table 2).

In case of $T$. gondii, the single occurrence was not detected in examined material. The coinfection of B. microti and $T$. gondii was reported in case of $2.3 \%$ of $C$. canis and $1.9 \%$ of $C$. felis felis. Co-occurrence of these protozoans was detected only in females (Table 2).

\section{Discussion}

In this study, new epidemiological data about the prevalence of B. microti and T. gondii in fleas collected from domestic cats and dogs were presented.

The first attempt of B. microti detection in fleas was made in 2013, however, the DNA of this protozoan was not reported in examined Xenopsylla cheopis, C. canis, C. felis and Cediopsylla inaequalis fleas [34]. In our study, the prevalence of this pathogen was $6.6 \%$ of $C$. felis felis and $9.1 \%$ of C. canis. B. microti is a species, which life cycle is adapted to the tick physiology. It belongs to organisms which are latent in improper conditions, thus the transmission of this protozoan from tick to another organism takes approximately 36 to $72 \mathrm{~h}$. This process is caused by a long time of sporoblasts activation and the production of sporozoites in the tick salivary glands. The active transmission of this pathogen by cat or dog fleas is probably impossible,
Table 1 Species and sex diversity of fleas collected from examined host species

\begin{tabular}{lllll}
\hline Host species & Flea species & Sex & \multirow{2}{l}{ Total number of fleas } \\
\cline { 3 - 4 } \cline { 3 - 4 } & & Female & Male & \\
\hline Felis catus & Ctenocephalides felis felis & 55 & 4 & $59(89.39 \%)$ \\
& Ctenocephalides canis & 4 & 3 & $7(10.61 \%)$ \\
Canis lupus familiaris & Ctenocephalides felis felis & 38 & 9 & $47(52.81 \%)$ \\
& Ctenocephalides canis & 29 & 8 & $37(41.57 \%)$ \\
& Pulex irritans & 3 & 0 & $3(3.37 \%)$ \\
& Archaeopsylla erinacei & 2 & 0 & $2(2.25 \%)$ \\
& Total number of fleas & $131(84.52 \%)$ & $24(15.48 \%)$ & $155(100 \%)$ \\
\hline
\end{tabular}

Table 2 The number and percentage of Ctenocephalides fleas collected from pets, infected with Babesia microti and Toxoplasma gondii

\begin{tabular}{|c|c|c|c|c|c|}
\hline \multirow[t]{2}{*}{ Flea species and sex } & & \multirow{2}{*}{$\begin{array}{l}\text { No. of studied } \\
\text { fleas }\end{array}$} & \multicolumn{2}{|l|}{1 pathogen } & \multirow{2}{*}{$\begin{array}{l}2 \text { pathogens } \\
\text { Babesia } \\
\text { microti + Toxo- } \\
\text { plasma gondii }\end{array}$} \\
\hline & & & Babesia microti & Toxoplasma gondii & \\
\hline \multirow[t]{2}{*}{ Ctenocephalides felis felis } & Female & 93 & $6(6.4 \%)$ & $0(0 \%)$ & $2(2.1 \%)$ \\
\hline & Male & 13 & $1(7.7 \%)$ & $0(0 \%)$ & $0(0 \%)$ \\
\hline Total number of Ctenocephalides felis felis & & 106 & $7(6.6 \%)$ & $0(0 \%)$ & $2(1.9 \%)$ \\
\hline \multirow[t]{2}{*}{ Ctenocephalides canis } & Female & 33 & $2(6.1 \%)$ & $0(0 \%)$ & $1(3 \%)$ \\
\hline & Male & 11 & $2(18.2 \%)$ & $0(0 \%)$ & $0(0 \%)$ \\
\hline Total number of Ctenocephalides canis & & 44 & $4(9.1 \%)$ & $0(0 \%)$ & $1(2.3 \%)$ \\
\hline
\end{tabular}


because of a short flea parasitizing period and inability to close the $B$. microti development cycle in the fleas body $[21,35,36]$. On the other hand, there is still lack of knowledge about the behavior of $B$. microti gamonts in the flea intestine, which would be decisive in determining the possibility of the passive transmission process.

Alimentary way of transmission does not clarify a high prevalence of $T$. gondii in many of herbivorous mammals (up to $75 \%$ ) [37, 38], wild rodents (up to $35 \%$ ) [39, 40] and fowl (even up to 100\%) [41], which should have limited contact with the invasive forms of this protozoan. For this reason, other ways of $T$. gondii transmission are considering, including - by blood-sucking arthropods [42-44]. Deryło et al. [45] as the first showed the experimental transmission of $T$. gondii in I. ricinus, when they found tachyzoites and bradyzoites in tissues of nymphs and females of this tick species. The first molecularly confirmed detection of $T$. gondii in I. ricinus was described in 2003, what initiated interest of this topic [28]. Presence of this species was reported in ticks collected from the north-eastern region of Poland. Moreover, in that study development of infection was confirmed in a culture of laboratory mice, as an effect of their previous inoculation by homogenate, composed of $T$. gondii infected $I$. ricinus ticks [31]. In another research, from the Upper Silesia Region in Poland, the presence of $T$. gondii was molecularly detected in questing I. ricinus, and also in ticks collected directly from the hosts. What is interesting, the prevalence of this protozoan in ticks, collected from dogs and cats in study of Asman et al. [46] was very high at this time and oscillated about $98 \%$. It suggested, that pets living in the Silesia Region are appropriate hosts for $T$. gondii, what confirmed the validity of our study. In contrast, a low prevalence of $T$. gondii in I. ricinus collected from Shetland ponies was reported $(2.99 \%)$, what may indicate, that these animals are not the competent hosts for this protozoan [47]. In other studies, the occurrence of $T$. gondii in D. reticulatus and Haemaphysalis longicornis was reported [23, 48]. Zhou et al. [48] conducted a study, which focused on showing the role of $H$. longicornis in transmission of T. gondii. In this experiment, the blood-feeding transmission in adult ticks was not observed, but ticks became infected when they ingest $T$. gondii, which was present in blood of mammals. Thereby, accidental ingestion of infected $H$. longicornis tick may induce a mechanism of $T$. gondii transmission between ticks and hosts. This way of transmission, could explain many cases of toxoplasmosis among herbivorous species. It is possible, because of a similar way of transmission in case of another protozoan species from the Apicomplexa type-Hepatozoon canis [48, 49]. In turn, Skotarczak [50] suggested, that if $T$. gondii is a species with asexual reproduction in different cells of intermediate hosts, which migrates also to monocytes and neutrophils that there is a possibility of its transmission to other hosts by other hematophagous arthropods.

Our paper presents the occurrence of $T$. gondii DNA in examined flea species. This protozoan is present only in fleas, which are also coinfected with $B$. microti. The prevalence of this co-occurrence in $C$. felis felis estimated at $1.9 \%$, while in case of $C$. canis-2.3\%. In our study, the DNA of T. gondii was detected only in females, what was probably caused by their larger number in both examined populations and a greater life activity correlated to the higher blood-sucking quantity, when they prepare to procreation [51].

The first cases of $B$. microti detection and coinfection of B. microti and T. gondii in Ctenocephalides fleas was shown in this study. The phenomenon of B. microti and T. gondii passive transmission (by swallowing an infected flea) by $C$. felis felis and C. canis may exist. However, it requires further research, in order to test the viability of gamonts in the flea intestine tract and the possibility of laboratory animals infection via oral route.

Acknowledgements The authors are thankful Professor Angelina Wójcik-Fatla PhD from the Witold Chodźko Institute of Rural Health in Lublin for kindly providing the control samples of Toxoplasma gondii and Babesia microti, and also the staff from veterinary clinics, animal shelters and pet grooming salons for their support in collection of material.

\section{Compliance with Ethical Standards}

Conflict of Interest The authors declare that they have no conflict of interest.

Ethical Approval This article does not contain any studies with human participants performed by any of the authors.

Open Access This article is licensed under a Creative Commons Attribution 4.0 International License, which permits use, sharing, adaptation, distribution and reproduction in any medium or format, as long as you give appropriate credit to the original author(s) and the source, provide a link to the Creative Commons licence, and indicate if changes were made. The images or other third party material in this article are included in the article's Creative Commons licence, unless indicated otherwise in a credit line to the material. If material is not included in the article's Creative Commons licence and your intended use is not permitted by statutory regulation or exceeds the permitted use, you will need to obtain permission directly from the copyright holder. To view a copy of this licence, visit http://creativecommons.org/licenses/by/4.0/.

\section{References}

1. Kunkle GA, Jones LJ, Petty P (2000) Immediate intradermal flea antigen reactivity in clinically normal adult dogs from south Florida, USA. Vet Dermatol 11:9-12. https://doi.org/10.104 6/j.1365-3164.2000.00151.x 
2. Bitam I, Dittmar K, Parola P, Whiting MF, Raoult D (2010) Fleas and flea-borne diseases. Int J Infect Dis 14:667-676. https://doi. org/10.1016/j.ijid.2009.11.011

3. Beck W, Boch K, Mackensen H, Wiegand B, Pfister K (2006) Qualitative and quantitative observations on the flea population dynamics of dogs and cats in several areas of Germany. Vet Parasitol 137:130-136. https://doi.org/10.1016/j.vetpar.2005.12.021

4. Dobler G, Pfeffer M (2011) Fleas as parasites of the family Canidae. Parasit Vectors 4:139. https://doi. org/10.1186/1756-3305-4-139

5. Thepparit C, Hirunkanokpun S, Popov VL, Foil LD, Macaluso KR (2013) Dissemination of bloodmeal acquired Rickettsia felis in cat fleas Ctenocephalides felis. Parasit Vectors 6:149. https:// doi.org/10.1186/1756-3305-6-149

6. Gálvez R et al (2017) Modelling the current distribution and predicted spread of the flea species Ctenocephalides felis infesting outdoor dogs in Spain. Parasit Vectors 10(1):428. https://doi. org/10.1186/s13071-017-2357-4

7. Pawełczyk O, Pająk C, Solarz K (2016) The risk of exposure to parasitic mites and insects occurring on pets in Southern Poland. Annals Parasitol 62(4):337-344. https://doi.org/10.17420/ap620 4.70

8. Pawełczyk O, Asman M, Solarz K (2019) The molecular detection of Anaplasma phagocytophilum and Rickettsia spp. in cat and dog fleas collected from companion animals. Folia Parasitol 66:020. https://doi.org/10.14411/fp.2019.020

9. Farkas R, Gyurkovszky M, Solymosi N, Beugnet F (2009) Prevalence of flea infestation in dogs and cats in Hungary combined with a survey of owner awareness. Med Vet Entomol 23:187-194. https://doi.org/10.1111/j.1365-2915.2009.00798.x

10. Bond R, Riddle A, Mottram L, Beugnet F, Stevenson R (2007) Survey of flea infestation in dogs and cats in the United Kingdom during 2005. Veterinary Rec 160:503-506. https://doi. org/10.1136/vr.160.15.503

11. Just FT, Gilles J, Pradel I, Pfalzer S, Lengauer H, Hellmann K, Pfister K (2008) Molecular evidence for Bartonella spp. in cat and dog fleas from Germany and France. Zoonoses Public Health 55:514-520. https://doi.org/10.1111/j.1863-2378.2008.01131.x

12. Tołkacz K et al (2017) Prevalence, genetic identity and vertical transmission of Babesia microti in three naturally infected species of vole, Microtus spp. (Cricetidae). Parasit Vectors 10:66. https:// doi.org/10.1186/s13071-017-2007-x

13. Kuźna-Grygiel W, Kołodziejczyk L (2000) Studies of liver of mice in the course of an experimental infection with Babesia microti II: histopathological studies on oxidative and antioxidative enzymes. J Protozool Res 10:24-30

14. Lobo CA, Rodriguez M, Cursino-Santos JR (2012) Babesia and red cell invasion. Curr Opin Hematol 19:170-175. https://doi. org/10.1097/MOH.0b013e328352245a

15. Brennan MB et al (2016) Transmission of Babesia microti parasites by solid organ transplantation. Emerg Infect Dis 22:18691876. https://doi.org/10.3201/eid2211.151028

16. Forrester K, Franco LG, Postelnicu R, Jacobs REA (2015) Haematologic complications from human babesiosis: a case report. New Microbes New Infect 8:148-149. https://doi.org/10.1016/j. nmni.2015.10.008

17. Humiczewska M, Kuźna-Grygiel W (1997) A case of imported human babesiosis in Poland. Wiadomości Parazytol 43:227-229

18. Hartelt K, Pluta S, Oehme R, Kimmig P (2008) Spread of ticks and tick-borne diseases in Germany due to global warming. Parasitol Res 103:109-116. https://doi.org/10.1007/s0043 6-008-1059-4

19. Siński E et al (2006) Babesia microti: prevalence in wild rodents and Ixodes ricinus ticks from the Mazury Lakes District of northeastern Poland. Int J Med Microbiol 296:137-143. https://doi. org/10.1016/j.ijmm.2006.01.015
20. Joseph JT et al (2012) Vertical transmission of Babesia microti United States. Emerg Infect Dis 18(8):1318-1321. https://doi. org/10.3201/eid1808.110988

21. Vannier E, Krause PJ (2012) Human babesiosis. N Engl J Med 366:2397-2407. https://doi.org/10.1016/j.idc.2008.03.010

22. Gubernot DM, Lucey CT, Lee KC, Conley GB, Holness LG, Wise RP (2009) Babesia infection through blood transfusions: reports received by the US Food and Drug Administration, 1997-2007. Clin Infect Dis 48(1):25-30. https://doi.org/10.1086/595010

23. Opalińska P, Wierzbicka A, Asman M (2016) The PCR and nested PCR detection of Borrelia burgdorferi sensu lato, Anaplasma phagocytophilum and Babesia microti in Dermacentor reticulatus F. collected i a new location in Poland (Trzciel, Western Poland). Acta Parasitol. 61(4):849-854. https://doi.org/10.1515/ ap-2016-0117

24. Wójcik-Fatla A, Bartosik K, Buczek A, Dutkiewicz J (2012) Babesia microti in adult Dermacentor reticulatus Ticks from Eastern Poland. Vector-Borne Zoonotic Dis 12(10):841-843. https://doi. org/10.1089/vbz.2011.0904

25. Tenter AM, Heckeroth AR, Weiss LM (2000) Toxoplasma gondii: from animals to humans. Int J Parasitol 30:1217-1258. https://doi. org/10.1016/s0020-7519(00)00124-7

26. Dubey JP et al (2006) Prevalence of Toxoplasma gondii in cats from Colombia, South America and genetic characterization of $T$. gondii isolates. Vet Parasitol 141:42-47. https://doi.org/10.1016/j. vetpar.2006.04.037

27. Hotop A et al (2014) Humoral immune responses in chickens and turkeys after infection with Toxoplasma gondii by using recombinant antigens. Parasitol Res 113:1473-1480. https://doi. org/10.1007/s00436-014-3788-x

28. Sroka J, Chmielewska-Badora J, Dutkiewicz J (2003) Ixodes ricinus as a potential vector of Toxoplasma gondii. Ann Agric Environ Med 10:121-123

29. Skuratowicz W (1967) Part XXIX. Fleas-Siphonaptera (Aphaniptera). In: Key to the classification of Polish insects vol. 53. Polish Entomological Society, Warsaw, pp 26-131

30. Rijpkema S, Golubić D, Molkenboer M, Verbeek-De KN, Schellekens J (1996) Identification of four genomic groups of Borrelia burgdorferi sensu lato in Ixodes ricinus ticks collected in a Lyme borreliosis endemic region of northern Croatia. Exp Appl Acarol 20:23-30. https://doi.org/10.1007/BF00051474

31. Sroka J, Wójcik-Fatla A, Zwoliński J, Zając V, Sawczuk M, Dutkiewicz J (2008) Preliminary study on the occurrence of Toxoplasma gondii in Ixodes ricinus ticks from north-western Poland with the use of PCR. Ann Agric Environ Med 15(2):333-338

32. Sroka J, Szymańska J, Wójcik-Fatla A (2009) The occurrence of Toxoplasma gondii and Borrelia burgdorferi sensu lato in Ixodes ricinus ticks from eastern Poland with the use of PCR. Ann Agric Environ Med 16:313-319

33. Wójcik-Fatla A, Szymańska J, Wdowiak L, Buczek A, Dutkiewicz J (2009) Coincidence of three pathogens (Borrelia burgdorferi sensu lato, Anaplasma phagocytophilum and Babesia microti) in Ixodes ricinus ticks in the Lublin macroregion. Ann Agric Environ Med 16:151-158

34. Torina A et al (2013) A molecular survey of Anaplasma spp., Rickettsia spp., Ehrlichia canis and Babesia microti in Foxes and Fleas from Sicily. Transbound Emerg Dis 60:125-130. https ://doi.org/10.1111/tbed.12137

35. Schorderet-Weber S, Noack S, Selzer PM, Kaminsky R (2017) Blocking transmission of vector-borne diseases. Int J Parasitol Drugs Drug Resist 7:90-109. https://doi.org/10.1016/j.ijpdd r.2017.01.004

36. Dantas-Torres F, Alves LC, Uilenberg G (2017) Babesiosis. In: Marcondes CB (ed) Arthropod borne diseases. Springer International Publishing, Cham, pp 347-353 
37. Witkowski L, Czopowicz M, Nagy DA, Potarniche AV, Aoanei MA, Imomov N, Mickiewicz M, Welz M, Szaluś-Jordanow O, Kaba J (2015) Seroprevalence of Toxoplasma gondii in wild boars, red deer and roe deer in Poland. Parasite 22:17. https:// doi.org/10.1051/parasite/2015017

38. Jokelainen P, Näreaho A, Knaapi S, Oksanen A, Rikula U, Sukura A (2010) Toxoplasma gondii in wild cervids and sheep in Finland: north-south gradient in seroprevalence. Vet Parasitol 171:331-336. https://doi.org/10.1016/j.vetpar.2010.04.008

39. Webster J (1994) Prevalence and transmission of Toxoplasma gondii in wild brown rats Rattus norvegicus. Parasitology 108:407-411. https://doi.org/10.1017/s0031182000075958

40. Dabritz HA, Miller MA, Gardner IA, Packham AE, Atwill ER, Conrad PA (2008) Risk factors for Toxoplasma gondii infection in wild rodents from Central Coastal California and a review of T. gondii prevalence in rodents. J Parasitol 94:675-683. https:// doi.org/10.1645/GE-1342.1

41. Dubey JP (2002) A review of toxoplasmosis in wild birds. Vet Parasitol 106:121-153. https://doi.org/10.1016/S0304 -4017(02)00034-1

42. Wójcik-Fatla A, Sroka J, Zając V, Sawczyn A, Cisak E, Dutkiewicz J (2015) Toxoplasma gondii (Nicolle et Manceaux, 1908) detected in Dermacentor reticulatus (Fabricius) (Ixodidae). Folia Parasitol 62:055. https://doi.org/10.14411/fp.2015.055

43. Shafy SA et al (2015) Detection of Toxoplasma gondii (Apicomplexa: Sarcocystidae) in the brown dog tick Rhipicephalus sanguineus (Acari: Ixodidae) fed on infected rabbits. Res J Parasitol 10:142-150. https://doi.org/10.3923/jp.2015.142.150

44. Guo M et al (2015) Prevalence and risk factors for Toxoplasma gondii infection in meat animals and meat products destined for human consumption. J Food Prot 78:457-476. https://doi. org/10.4315/0362-028X.JFP-14-328
45. Deryło A, Toś-Luty S, Dutkiewicz J, Umiński J (1978) Badania nad udziałem kleszczy Ixodes ricinus L. w biologii i przenoszeniu Toxoplasma gondii. Wiad Parazytol: 585-595

46. Asman M et al (2015) Detection of protozoans Babesia microti and Toxoplasma gondii and their co-existence in ticks (Acari: Ixodida) collected in Tarnogórski district (Upper Silesia, Poland). Ann Agric Environ Med 22:80-83. https://doi. org/10.5604/12321966.1141373

47. Adamska M, Skotarczak B (2017) Molecular evidence for Toxoplasma gondii in feeding and questing Ixodes ricinus ticks. Ticks Tick Borne Dis 8:259-261. https://doi.org/10.1016/j.ttbdi s.2016.11.009

48. Zhou Y, Zhang H, Cao J, Gong H, Zhou J (2016) Epidemiology of toxoplasmosis: role of the tick Haemaphysalis longicornis. Infect Dis Poverty 5:14. https://doi.org/10.1186/s40249-016-0106-0

49. Baneth G, Samish M, Shkap V (2007) Life cycle of Hepatozoon canis (Apicomplexa: Adelorina: Hepatozoidae) in the tick Rhipicephalus sanguineus and domestic dog (Canis familiaris). J Parasitol 93:283-299. https://doi.org/10.1645/GE-494R.1

50. Skotarczak B (2016) The role of ticks in transmission cycle of Toxoplasma gondii. Ann Parasitol 62:185-191. https://doi. org/10.17420/ap6203.52

51. Rust MK (2017) The biology and ecology of cat fleas and advancements in their pest management: a review. Insects 8:118. https://doi.org/10.3390/insects8040118

Publisher's Note Springer Nature remains neutral with regard to jurisdictional claims in published maps and institutional affiliations. 